\title{
DA CERTEZA: HUSSERL E WITTGENSTEIN
}

\author{
José Manuel Heleno
}

1. Em vez de uma forma delirante de verdade, a certeza atesta a forma tranquila da verdade se oferecer a cada um de nós. Não basta, de facto, dizer apenas que a certeza duplica a verdade, como se, com esse gesto, se limitasse a repeti-la. O que é quanto a nós interessante é o facto da certeza acrescentar algo, isso que, ao ser excessivo, faz da verdade index sui. E é inútil multiplicar os critérios e afirmar que há verdade cada vez que existem critérios determinados, já que é a certeza, precisamente, aquilo que permite oferecê-los com evidêncial.

Relembremos o facto da história da filosofia poder oscilar entre duas posições. A primeira considera a certeza como algo que se poderia encontrar, quer confiando na razão, quer depurando-a de tal forma que esta encontraria a evidência e rejubilaria por conhecer tal fundamento. Neste sentido, as várias formas de cepticismo serviriam não apenas para fortalecer a razão como também a crença de que era possível encontrar a verdade e, ainda mais, a certeza dessa mesma verdade. É neste contexto que aparecem as ideias claras e distintas, a intuição, ou até a noção de inato. A segunda posição que podemos encontrar na história da filosofia remete-nos não tanto para o fim de um trajecto mas, ao invés, para o início do mesmo. Expliquemo-nos: mais do que ver na certeza aquilo que se poderia encontrar, esta seria antes o fundamento de qualquer procura, já que a ser antepredicativa seria prévia a qualquer verdade. Seria a certeza que fundamentaria toda a linguagem, embora nem sempre se explicasse - justamente porque tal não era explicável - a raiz desse mesmo fundamento.

Wittgenstein e Husserl, como veremos, perfilham este ponto de vista.

\footnotetext{
1 Cf. o texto de Daniel C. Dennett. "Fé na Verdade" (in Disputatio, 3. Nov/1997, pp. 3-21). A "verdade" é tida como um bem precioso que o cepticismo pós-modeme tende a esvaziar. No seu texto, Dennett mostra como precisames de acreditar na verdade em termos antropológicos e culturais, e que "a ciência e a tecnologia da procura da verdade" constitui um valioso bem que o ocidente pode exportar (p. 21). Parece-nos que o importante é questionar as certezas ou as crenças que estão subjacentes a esta "fé na verdade".
} 
Todavia, podemos também encontrar Husserl na primeira perspectiva, não apenas porque é esse o intuito desse neocartesianismo que é a fenomenologia, como também devido à insistência reiterada pelo próprio Husserl no sentido de se poder chegar a algo apodíctico. Se, em contrapartida, esta posição era insustentável para Wittgenstein, tal deve-se à maneira com que encarava a actividade filosófica.

2. As páginas que se seguem têm o intuito de pensar a questão da certeza a partir dos filósofos que acabámos de referir. É que, para além de ser convicção nossa que se pode compreender melhor Husserl e Wittgenstein tomando como pedra de toque a noção de certeza, é ainda pertinente, parece-nos, ver nesta questão um problema central da história da filosofia.

O facto de termos certezas surge da convicção que os seres humanos partilham um mundo. Ou então, é o facto de existir um mundo comum, onde nos servimos da linguagem para transmitir experiências, que nos leva a dizer que há certezas. A existência de um sentido, inviabiliza, por si mesmo, a linguagem privada, antes mostra que estamos já e sempre no mundo, algo que podemos partilhar com os outros. É por isso que a certeza põe a questão da intersubjectividade no centro da filosofia - e sabemos que tanto Husserl como Wittgenstein dedicaram uma parte significativa das suas reflexões à questão do solipsismo.

Com efeito, mostrar a relação entre o ego e o alter-ego ou considerar a impossibilidade da linguagem privada, aponta, em Husserl e Wittgenstein, para a necessidade de compreender a relação entre os vividos da consciência e um mundo comum, estável e partilhado. A Lebenswelt (Husserl) e a Lebensform (Wittgenstein) são respostas possíveis a estas questões.

3. Como é que as coisas são? Em Über Gewissheit ${ }^{2}$, Wittgenstein fala-nos do modo como as coisas parecem ser para nós, embora longe da distinção kantiana entre fenómeno e númeno e ainda mais de uma possível ilusão desse parecer. Ao fazê-lo, mostra-nos que estamos imersos dentro de um sistema que nos precedeu e que se consubstancia em jogos de linguagem determinados. Tudo o que pode ser dito é dito dentro desse sistema, embora a palavra sistema não tenha aqui o significado de rígida totalidade a que, frequentemente, fazemos alusão. Se tudo se passa no interior de um sistema, é porque "as minhas convicções formam de facto um sistema, uma estrutura" (§ 102), ou então, há proposições rígidas que se tornam fluídas e vice-versa (cf. § 96).

Dir-se-á que tudo depende da maneira como se usam as proposições - e o mesmo é válido para as proposições matemáticas. Há então perguntas e

${ }^{2}$ L. Wittgenstein, Über Gewissheit/ Da Certeza, Lisboa, Edições 70, 1998. As nossas citações remetem para esta edição. 
dúvidas que só têm sentido porque se fundamentam em proposições isentas de dúvida; proposições que "são como dobradiças em volta das quais giram as dúvidas" (cf. § 341). E é do mesmo modo que se coloca a questão das regras: não aprendemos regras mas antes o cálculo que elas permitem. Pensar numa aprendizagem ostensiva das regras é não perceber o modo como funcionam os jogos de linguagem. Para Wittgenstein se há falta de nitidez "é a da demarcação entre regra e proposição empírica" (§ 319).

Compreende-se assim o facto das regras se "usarem" sem que as saibamos explicar. Escreve o autor em The Blue Book o seguinte: "Somos incapazes de circunscrever claramente os conceitos que usamos; não porque não sabemos a sua definição real, mas porque não há definição real para eles"'3. É neste sentido que podemos dizer que não é só o tempo que não tem uma verdadeira definição - e que seria assim, estulto, procurar saber qual é a sua origem -, também uma cadeira, por exemplo, não tem uma verdadeira definição se entendermos por isso, uma vez mais, algo que se assemelhe à obsessão da tradição filosófica em chegar à essência dos objectos (ibid., p. 26). A haver filosofia ela será apenas descritiva, o que equivale a dizer, em termos fenomenológicos, que nos limitamos a descrever aquilo que aparece, como se dá de forma evidente numa consciência (ou numa linguagem) e o modo como os juízos se constróem a partir dessas evidências.

A heterogeneidade dos jogos de linguagem, a sua elasticidade, significa que algo só faz sentido dentro de uma imagem do mundo. Estamos, por isso, cheios de certezas ("Não posso deixar de acreditar..."; Da Certeza, op. cit., § 277), e a própria noção de dúvida não teria sentido sem certezas que a viabilizassem. Errar ou pôr em dúvida determinadas certezas significaria o desabamento do sistema. Ora, para nós, que estamos dentro de um sistema, tudo fala a favor dele e nada contra. Já o Wittgenstein do Tratado Lógico-Filosófico referia que os limites da linguagem eram os do mundo, pois jamais poderíamos estar fora da linguagem. Compreende-se, ainda, que o próprio jogo entre perguntar e responder só tenha sentido a partir de uma rede de convicções. "É o quadro de referências herdado - insiste Wittgenstein (ibid., § 94) - que me faz distinguir o verdadeiro do falso".

Aprendemos a ter certezas, pois é isso que, simultaneamente, dá segurança ao indivíduo que somos e consistência ao próprio mundo. Começar a filosofar será recuar indefinidamente na cadeia das certezas, em busca do seu fundamento. Contudo, jamais o poderíamos fazer se não nos apoiássemos numa imagem do mundo (Weltbild); em inúmeras certezas que proporcionam, elas mesmas, fundamento ao próprio processo de inquirição. Atente-se, no entanto, que a dificuldade reside em compreender "a falta de fundamento das nossas convicções" ( $\$ 166$ ) ou o facto de não termos "razões fundamen- 
tadas para o modo como procedemos" ( $§ 307)$ pois, no limite, não poderemos invocar a experiência como fundamento dos nossos juízos (cf. § 130 e 131). Dizer que a experiência é a causa das nossas convicções não é o mesmo que dizer que ela é o fundamento. Afirmar, por exemplo, que esta certeza advém desta experiência é diferente de atestar que encontrei o fundamento dessa convicção na experiência. Para Wittgenstein a experiência poderia ter originado outras certezas. E se posso sempre retorquir dizendo que consigo provar esta ou aquela proposição empírica, é bom que se acrescente que o faço a partir de uma totalidade de juízos, de um corpo de certezas que necessitariam elas mesmas de ser fundamentadas. O essencial não está no resultado do problema ou da prova, mas sim no modo como um e outro se enunciam.

Assim, ao verificar exaustivamente a proposição que diz que estas mãos são as minhas mãos, não ponho em dúvida um possível engano dos meus olhos, mas apenas aquilo que eles vêem. Aquilo de que duvido é o mais frágil; é tão só o que o conjunto das minhas convicções permite pôr em dúvida. Não apenas o sentido de hipótese, verificação ou prova, só tem sentido dentro de um sistema de certezas, como também o modo como se aplica a regra é já determinado. Para Wittgenstein "a verdade das minhas afirmações é a prova da minha compreensão dessas afirmações" (§ 80). Ou então: "Realmente, "a proposição é verdadeira ou falsa" só significa que tem de ser possível decidir a favor ou contra ela, mas não diz qual o fundamento para essa decisão" (§ 200; itálicos nossos). Mais à frente ( $§ 253)$, escreve-se ainda: "Na raiz de uma convicção bem fundamentada encontra-se uma convicção não fundamentada"4.

4 Poder-se-á articular a noção de certeza com as questões desenvolvidas em Bemerkungen über Frazer Golden Bough ? (in L. Wittgenstein, Philosophical Occasions. 1912-1951, Edited by James Klagge and Alfred Nordmann, Hackett Publishing Company, 1993, pp. 115-155). Embora Wittgenstein não o refira directamente, podemos dizer que esta é, efectivamente, uma das questões centrais do texto referido. Vejamos porquê.

Wittgenstein considera, contra Frazer, que a explicação da magia não tem poder para substituir a impressão que a mesma suscita. O primitivo, que vive dentro de um sistema "mágico", interpreta o mundo de forma a que este tenha um sentido a partir dos símbolos e da linguagem, estando fora de causa que este sentido seja um erro. Verdade e falsidade são termos científicos que não têm aplicabilidade na mundivivência mágica ou religiosa. O que Wittgenstein está interessado em realçar é que o primitivo tem convicções que, de uma maneira ou outra, acabam sempre por se confirmar. Ora, é extraordinário que se passe o mesmo com o homem actual. A ciência aparece então como uma versão do mundo, diferente, e não melhor, do que outras.

Assim, dizer, por exemplo, que o ponto de vista mágico ou religiosos são erros é antecipar uma teoria. De facto, só antecipando uma teoria tem sentido falar em erro (cf. pp. 118-119). E se dissermos a alguém que a sua religião, o seu Deus, está errado, isso não é suficiente para dissuadi-lo das suas conviç̧ões. Daí a expressão de Wittgenstein: "Nur beschreiben kann man hier und sagen: so ist das menschliche Leben" ("Aqui apenas se pode descrever e dizer: assim é a vida humana"; p. 120). E acrescenta ainda que a explicação é demasiado incerta, pois não substitui a força da impressão. É que a impressão não é vivida como uma hipótese, enquanto a explicação sim. A impressão, diremos nós, é vivida como uma certeza. 
Também o autor do Livro Azul mostra que não tem sentido fazer perguntas do género: "Este quarto tem um comprimento?" ou até "tens a certeza que sabes o que desejas?" (op. cit. p. 30). Trata-se de perguntas que não fazemos, pois seria absurdo pôr em dúvida aquilo que elas pretendem interrogar. A não ser, acrescenta Wittgenstein, em casos determinados que denomina de "enunciados gramaticais" (gramatical statement).

Um dos tópicos fundamentais do Da Certeza é a discussão com Moore, designadamente a questão do "eu sei". Para Wittgenstein o "eu sei" e o "eu creio" pertencem a categorias diferentes (§ 308). O primeiro é, amiúde, supérfluo, pois nada acrescenta à minhas razões, para além do seu "toque" enfático, e é devido a isso que não se pode demonstrar o "seu sei". Parece-nos que Wittgenstein critica o "eu sei" na mesma base com que o faz para a noção de "regra". É preciso ver como usamos cada uma destas noções - só assim poderemos compreendê-las. A defesa que Moore faz do senso comum, considerando que há verdades empíricas que são fundadas na evidência, faz um uso indevido da expressão "eu sei". Para Wittgenstein o "eu sei" não garante que saibamos efectivamente. "“"Eu sei isso" - escreve o autor Da Certeza (\$175) -, digo para outra pessoa; há aqui uma justificação; mas não há nenhuma para a minha convicção". A certeza tem assim a marca da objectividade. É aquilo que é partilhado por uma comunidade de falantes e da qual é impossível duvidar.

Somos então treinados para adquirir certezas, pois é essa a condição da nossa existência como seres que falam e pensam, têm dúvidas e expectativas. A linguagem veicula um mundo certo onde nos movemos do nascer ao morrer. E mesmo que os jogos de linguagem possam ser sofisticados, a ponto de os próprios participantes os questionarem através do exercício da dúvida, a insistência de Wittgenstein na noção de acção é notória. Ao agirmos, somos treinados para actuar a partir e dentro de uma determinada imagem do mundo.

4. Vejamos agora alguns dos textos em que Husserl ${ }^{5}$, um dos autores que se propôs elucidar fenomenologicamente o juízo predicativo ao investigar a sua origem, analisou a questão da certeza. Ao começar por referir a noção de juízo proposta por Aristóteles - o juízo apofântico -, o autor interroga-se se o esquema " $S$ é $p$ " esgotará a compreensão do mesmo. Ora, o pressuposto de que Husserl parte reside na convicção de que ainda antes de qualquer reflexão sobre a lógica, há um mundo de significações que está já e sempre ao nosso dispor. Para isso não importa atender apenas às condições formais do acto de conhecer, pois é necessário interrogar os "caracteres

${ }^{5}$ E. Husserl, Erfahrung und Urteil. Untersuchungen zur Genealogie der Logik. Trad. fr. par

D. Souche, Expérience et jugement. Recherches en vue d'une généalogie de la logique,

Paris, PUF, 1970. 
subjectivos da intuição", a evidência, que nos permite falar num juízo verdadeiro.

Ao descurar esta análise do juízo, a lógica tradicional remetia a questão da evidência para a psicologia sem ver o alcance fenomenológico da mesma. Para Husserl, em contrapartida, há um dado prévio: o objecto sobre o qual incide o juízo, ente que tem de ser dado previamente para que qualquer juízo possa existir enquanto tal. É a evidência, precisamente, que nos dá esses objectos na sua ipseidade, não existindo juízo predicativo que a não pressuponha. Devemos então diferenciar a evidência originária, antepredicativa evidência em que os objectos são dados previamente -, da evidência do próprio juízo predicativo. A reflexão fenomenológica incidirá sobre a primeira e daí, uma vez mais, a sua diferença em relação à lógica tradicional.

Ao propor-se efectuar uma indagação fenomenológica, Husserl mostra que os juízos imediatos se apoiam em conhecimentos imediatos e estes, por sua vez, em evidências originárias. Uma teoria genética do juízo acabará assim por tomar em consideração aquilo que Husserl chama experiência, isto é, a evidência de objectos individuais, de substractos. Escreve: "Os substractos originários são então indivíduos, objectos individuais" (cf. § 5 e seg.), e são eles que intervêm nos juízos. Ora, a experiência antepredicativa, ao dar os substractos originários, é feita num solo universal, apoiada numa certeza simples e imediata de objectos que é, para Husserl, o mundo. E acrescenta (§ 7): "Este solo universal da crença no mundo é o que pressupõe toda a prática, tanto a prática da vida como a prática teórica do conhecer". $\mathrm{E}$ ainda: "A consciência do mundo é uma consciência que tem por modo a certeza da crença". Se toda a actividade do conhecimento tem o mundo como solo, então os objectos estão já e sempre aí, dados passivamente. O ser aparece como "crença passiva", um campo que a consciência tem disponível. Conhecer é uma disponibilidade - e o ser é o pressuposto dessa disponibilidade $^{6}$.

5. Pensamos nós que esta noção de evidência pré-originária e antepredicativa se pode relacionar com a noção de certeza em Wittgenstein. Se este fala em "tesouros", Husserl fala em "depósitos", isto é, aquilo que faz do

${ }^{6}$ Num texto de 1934, "A Terra Arquioriginária não se Move" (manuscrito de Husserl publicado por M. Farber em 1940 nos Philosophical Essays in Memory of E. Husserl. Cf. a trad. fr. de Didier Franck, in La Terre ne se meut pas, Paris, Les Éditions de Minuit, 1989, pp. 7 -29), a terra aparece como essa forma originária de representação que é a fonte de todas as representações. A terra, qual "arquilar", não se move nem está em repouso, é antes em relação a ela que movimento e repouso ganham sentido (cf., trad. fr. op. cit., p. 12). Há então corpos-solos, como os automóveis, os comboios, os navios, que são pensados e "vividos" a partir da evidência da terra solo: é ela que está pressuposta em todos nós. Esta representação primordial é, diremos nós, o solo passivo da crença e da certeza - o que nos aproxima do autor Da Certeza onde, curiosamente, um dos exemplos privilegiados é a terra. 
julgar simples uma modificação intencional do julgar evidente. Ora, a certeza wittgensteiniana é também um "depósito", pois antecede qualquer juízo possível e serve de fundamento para que o acto de julgar se realize. Pensamos que em ambos os autores se deve enfatizar o facto de não existir experiência que não tenha o seu próprio horizonte. Husserl fala mesmo em horizonte interno e externo, considerando que num caso e noutro há potencialidades que podem aceder à consciência e tornarem-se, assim, actos. Falar em horizonte é então mencionar a transcendência do sentido, isso que está invariavelmente vinculado a cada apercepção simples. "Assim - escreve Husserl em Experiência e Juízo (§ 8) - a estrutura do conhecido e do desconhecido é uma estrutura fundamental da consciência do mundo".

Por mundo como horizonte entende-se o facto de uma generalidade indeterminada se unir a uma particularidade determinada. Ora, são os textos terminais de Husserl e de Wittgenstein que sublinham exaustivamente esta questão. Para o primeiro (ibid., § 10), "é sobre as evidências da experiência que devem finalmente fundar-se todas as evidências predicativas". Compreende-se assim o retorno ao mundo, esse solo universal de todas as experiências singulares. Quando o autor afirma que as ciências vestem o mundo de ideias, fá-lo sempre no sentido de valorizar o ente pré-dado, isto é, o facto do mundo não ser em si como quer a ciência, mas ser antes a experiência originária do mundo da vida que é o mais importante, pois ela está aquém das idealizações e é, na verdade, o fundamento das mesmas. Legitimar a doxa é então regressar à experiência antepredicativa. Mas significará isso regressar a uma subjectividade escondida e, por isso mesmo, à psicologia? Husserl, como sabemos, reprova à psicologia o facto de não ir suficientemente longe na sua indagação: só a atitude fenomenológica pode dar conta das operações subjectivas da consciência, ou seja, o modo como se constitui um mundo possível.

Vejamos, de forma sucinta, como o texto da Krisis $^{7}$ aborda estas questões. Relembremos a crítica ao positivismo científico que, ao valorizar os factos, tinha uma imagem errónea da ciência. Husserl diz mesmo que o "positivismo (...) decapita a filosofia", impedindo a vitória da razão e o ultrapassar da crise que perpassa as ciências europeias. Para que a razão universal se manifeste e se possa retomar o enigma da subjectividade é necessário renovar a filosofia na sua essência. O Renascimento deu um novo alento para a construção de um novo sistema teórico, capaz de revigorar a filosofia e dar um novo rosto à liberdade humana.

Sabemos que Descartes e Galileu merecem a atenção de Husserl pelo facto de terem dado um passo significativo em direcção à mutação filosófica. Ao referir-se ao pensador que conduziu a matematização da natureza a uma 
concepção inaudita (Galileu), Husserl fala no mundo empírico e na "necessidade de acreditar em um mundo" (cf., p. 28). Fá-lo no intuito de mostrar que percepcionamos corpos na intuição sensível e que a imaginação parte dessas formas sensíveis e altera-as. É neste contexto que entra a geometria, essa capacidade de construirmos formas-ideais. A geometria é então o nome que o pensador alemão dá à elaboração sistemática de formas, "enquanto aproximação de formas ideais".

Sem nos desviarmos do propósito da nossa reflexão, é digno de registo o facto de Husserl começar a Krisis sublinhando a importância da geometria e, em contraponto, o facto de representarmos o mundo a partir de um hábito, de um estilo (cf. op. cit., p. 36). Significa isto que a matemática e a geometria são necessárias porque idealizam formas a partir de $u m$ mundo que nos liga, e todos "os momentos da experiência intuitiva indicam qualquer coisa deste mundo, desta realidade" (ibid., p. 39).

Ora, na terceira parte da Krisis insiste-se que o caminho em direcção à fenomenologia transcendental parte do mundo da vida. Se ao percepcionarmos intuímos o ente, é preciso não esquecer as "variações presentificativas" que daí decorrem. Escreve Husserl que "todo o pensamento científico e toda a problemática filosófica comportam evidências prévias: que o mundo é, que ele está sempre antecipadamente aí (...)" (ibid., p. 126). É assim que se parte sempre de pressupostos subjectivos e relativos que se alicerçaram em hábitos. E é este reino, precisamente, que não podemos deixar entregue ao anonimato. A insistência de Husserl estende-se por inúmeras páginas, mostrando-se que "um tratamento teórico radical do mundo é o tratamento interno sistemático e puro da subjectividade "exteriorizando-se" ela mesma no exterior" (ibid., p. 129). É esta evidência ou certeza que importa então interrogar de forma radical.

Curiosamente, autores como Alfred Schutz ${ }^{8}$, tentaram aplicar o método fenomenológico ao mundo social. Numa tentativa de elucidar fenomenologicamente o mundo da vida, Schutz mostra como conhecimento e acção são atitudes intersubjectivas, o que faz com que a estrutura do mundo da vida seja uma realidade social. Baseando-se fundamentalmente nos termos terminais de Husserl, Schutz considera que somos governados por motivos pragmáticos, isto é, que o mundo quotidiano é tido como uma realidade inquestionável, precisamente aquilo que se "toma como verdadeiro" (to take for granted; fraglos gegeben) e onde me aceito e aceito os outros de forma inquestionável. Sem dúvida que, como o próprio Husserl referiu, há um horizonte de dúvidas que pode eventualmente circunscrever as minhas evidências, pois estas fluem sem deixar de existir um "background of indeterminacy". Irrecusável é, no entanto, a existência de um "stock" de conhecimentos que

${ }^{8} \mathrm{Cf}$. Alfred Schutz and T. Luckmann, The Structures of the Life-World, Northwestern University Press, Evanston, 1973. 
me dão a solução dos problemas e me possibilita viver a evidência, o familiar. Escreve Schutz: "A sucessão de experiências na atitude natural forma tipicamente uma cadeia de auto-evidências" (op. cit., p. 10). E se estas evidências podem reformular-se é porque o meu conjunto de conhecimentos não é um "sistema logicamente integrado", antes algo que flui mas que nem por isso deixa de perder o seu carácter inquestionável enquanto dura. Ora, é nesta tentativa de analisar o mundo quotidiano a partir de uma metodologia fenomenológica que poderemos também encontrar reflexões afins às do autor Da Certeza.

Quando Wittgenstein, em The Big Typescript", afirma que a "naturalidade do mundo exprime-se precisamente no facto de a linguagem só o denotar a ele e só o poder denotar a ele", mostra esta exigência do mundo que encontramos em Experiência e Juízo. Mas o que é interessante é o facto de Wittgenstein falar em "linguagem" enquanto Husserl, em inúmeros textos, refere exaustivamente as "operações subjectivas" que possibilitam esta exigência do mundo. Significará isto que a questão da certeza é filtrada em Wittgenstein pela linguagem enquanto Husserl focaria antes o modo como um mundo possível se constitui na consciência? Pensamos que sim, embora Husserl, como veremos no parágrafo seguinte, tenha também referido a relação entre "formação do sentido" e "linguagem". É assim numa dupla perspectiva que se enraíza a certeza: ora vimos a certeza da experiência a partir da linguagem ora tomamos em consideração a evidência pré-originária que se dá na consciência.

6. Num dos últimos escritos de Husserl ${ }^{10}$, devemos prestar atenção àquilo que o filósofo denomina de "formação do sentido" (Sinnbildung). Efectivamente, e numa acepção "epistemológica" - que importa esclarecer o alcance -, trata-se de uma forma de "questionar às avessas" (Rückfrage) o modo como o sentido se sedimentou e se fez humano. Geometria é o nome que Husserl dá às "disciplinas que tratam de formas das quais a existência matemática se manifesta na espaço-temporalidade pura" (ibid., p. 174). Designa-se assim, com um nome genérico, aquilo que abrange as formas lógicas que conduziram às ciências tal como as pensamos.

Atente-se que o empreendimento husserliano é histórico num aspecto que importa elucidar. Ao querer fazer a arqueologia do sentido é, na verdade, um repensar desse mesmo sentido e da certeza que lhe é substancial que

${ }^{9}$ Cf. a tradução de António Zilhão dos $\S \S 86-93$ deste texto, publicado entre nós na revista Crítica, n. ${ }^{\circ}$ 6, Maio de 1991, pp. 3-20. Cf. também Philosophical Occasions. 1912-1951, op. cit., pp. 158-199.

10 Referimo-nos uma vez mais a Die Krisis der europäischen Wissenschaften und die transzendentale Phänomenologie (Husserliana, Vol. VI), mais propriamente a um dos seus anexos intitulado "A Origem da Geometria". Doravante citaremos este texto a partir da tradução francesa de Jacques Derrida (L'origine de la géometrie, Paris, PUF, 1999 (1. ed. 1962). 
importa levar a cabo. Assim, como é que a geometria se solidificou historicamente? O que é a tradição? Para Husserl tradição é sinónimo de sentido, na qual estamos sempre e já, isto é, estamos sempre e já na evidência, na certeza. Mas o que é extraordinário é que somos nós, humanos, que criámos esta tradição e, a fortiori, o mundo cultural em que estamos imersos. A tradição vai-se construindo, camada sobre camada, sendo esta dimensão que nos falta interrogar de forma radical.

Se é certo que houve uma passagem de uma produção espiritual subjectiva para uma objectividade ideal, falta interrogar como podemos nós compreender, na história do pensamento, o trânsito daquilo que começa por ser válido para um para o que é válido para todos, isto é, como é que as descobertas se tornam "património" da humanidade e fazem, assim, parte das suas certezas. Em A Origem da Geometria, Husserl pretende então repensar a "teleologia universal da Razão", ou seja, o facto de nos movermos todos no mesmo horizonte de conhecimento que nos faz estar dentro de uma tradição. Sem dúvida que a linguagem tem a capacidade de comunicar e sedimentar o sentido, a ponto da certeza adquirir uma função supratemporal. A linguagem - que, como escreve Husserl, "procura, por assim dizer, a sua carne linguística" (p. 181) - permite fazer a mediação entre o intratemporal e a objectividade ideal, entendendo-se por tal o facto de um sentido ser partilhado. Escreve Husserl: "É precisamente a este horizonte de humanidade que pertence a linguagem universal. A humanidade conhece-se primeiramente como comunidade de linguagem imediata e mediata" (p. 182). Por outro lado, é a linguagem que permite a identificação e reidentificação, passiva ou activa, do sentido. A certeza é assim repetição e rememoração. Husserl sabe bem que não cessamos de "reactivar" o sentido, isto é, de reactivar a evidência e a certeza, pois é isso que permite "identificar" os entes.

$\mathrm{O}$ que Wittgenstein não poderia aceitar é esta necessidade e exigência de uma espécie de arqui-história; não uma história factual mas antes uma história que desse o fundamento a priori e universal da formação do sentido. Husserl demarca-se de uma história dos factos, justamente porque ela mesma está dentro daquilo que pretende explicar. Ora, o que é preciso é esclarecer o horizonte no "qual penetra todo o acto de questionar". Husserl sonha assim com uma ciência que pode fazer a sua aparição como aeterna veritas ou capaz de desvendar o que está subjacente a uma teleologia universal da razão (cf. p. 213 e 215).

Uma vez mais, o que se deve assinalar é o contraste entre esta ânsia de uma filosofia como ciência de rigor (Husserl) e a necessidade de uma filosofia terapêutica em luta contra o feitiço da linguagem (Wittgenstein). Todavia, tal distância entre os pensadores referidos não impediu a proximidade aquando de uma reflexão sobre a certeza, isso que não cessa de se antecipar e que a linguagem veicula e solidifica. Ora, só uma atenção constante à linguagem ou à tradição permite lançar alguma luz sobre a "formação do sentido". 


\section{Résumé}

La finalité de "La Certitude: Husserl et Wittgenstein" c'est penser la constituition du sens, surtout l'édification de la certitude dans la réflexion de Husserl et Wittgenstein. Dans les textes terminaux des auteurs considérès, il y a une approximation entre les démarches que un et autre poursuivent. Nous analysons $\ddot{U}$ ber Gewissheit et textes de Husserl (Erfahrung und Urteil; Krisis) qui peuvent élucider ce qu'ils pensent sur la vérité en tant que certitude, croyance ou jugement anté-prédicative. C'est avec le langage et la tradition que notre réflexion s'achève. Une attention à la formation du langage et à l'action de la tradition peuvent ainsi éclaircir la formation du sens, c'est-à-dire, la certitude. 